\title{
Multisystem langerhans cell histiocytosis with thymic involvement diagnosed with anterior mediastinal mass in a 2-month-old boy
}

\author{
Funda Tekkeşin ${ }^{1}$, Arzu Okur ${ }^{1}$, Betül Emine Derinkuyư ${ }^{2}$, Nalan Akyürek ${ }^{3}$, Aynur Oğuz ${ }^{1}$, \\ Ceyda Karadeniz ${ }^{1}$, Faruk Güçlü Pınarlı ${ }^{1}$ \\ ${ }^{1}$ Division of Pediatric Oncology, Department of Pediatrics and Departments of ${ }^{2}$ Radiology and ${ }^{3}$ Pathology, Gazi University \\ Faculty of Medicine, Ankara, Turkey. \\ E-mail: tekkesinfunda@gmail.com \\ Received: 27th November 2015, Revised: 19th January 2016, Accepted: 1st March 2016
}

\begin{abstract}
SUMMARY: Tekkeşin F, Okur A, Derinkuyu BE, Akyürek N, Oğuz A, Karadeniz C, Pınarlı FG. Multisystem langerhans cell histiocytosis with thymic involvement diagnosed with anterior mediastinal mass in a 2 month-old boy. Turk J Pediatr 2016; 58: 424-428.

Thymus gland involvement in Langerhans cell histiocytosis ( $\mathrm{LCH}$ ) is usually part of multi-system disease and may be more common than previously recognized. However, thymic involvement causing an anterior mediastinal mass is an extremely rare presentation of multisystem LCH. Here we report a 2-month-old-boy admitted to hospital with a giant anterior mediastinal mass with multisystem LCH involving the thymus, lungs, liver and skin. The differential diagnosis of mediastinal mass in children should also include $\mathrm{LCH}$, especially multisystem disease. $\mathrm{LCH}$ should also be kept in mind in the differential diagnosis of skin lesions in infants, even if spontaneous regression occurs.
\end{abstract}

Key words: Langerhans cell histiocytosis, thymus, skin, infant.

Langerhans cell histiocytosis $(\mathrm{LCH})$ is a rare disease of unknown cause characterized by the infiltration and accumulation of monocytes and large histiocytes in different tissues ${ }^{1}$. Although patients may present at any age, median age at presentation is 30 months $^{2}$. Thymus involvement, extremely rare and usually part of multisystem disease, has only been mentioned in few case reports and small series ${ }^{3-5}$. Here we present a case of multisystem $\mathrm{LCH}$ diagnosed with an anterior mediastinal mass at a very young age who had skin involvement of $\mathrm{LCH}$ with spontaneous regression during newborn period.

\section{Case Report}

A 2-month-old boy was referred to our center with cough and wheezing without any serious respiratory distress. Patient's history revealed that he was admitted to another hospital when he was five days old with papular and vesicular rash all over his body including his face, and especially prominent in his groins.
He was hospitalized and treated with antiviral and antibacterial agents for about one week until his blood cultures and viral markers for varicella zoster and herpes simplex were found to be negative. He had also seborrheic dermatitis diagnosed as "cradle cap". His rash was resolved and patient had no other complaints until he was 2 months old.

On physical examination he was a welldeveloped, well-nourished child with no fever and no tachypnea. He had seborrheic dermatitislike lesions over his scalp and groins, decreased respiratory sounds on the left and prominent abdomen with hepatomegaly $7 \mathrm{~cm}$ below the right costal margin. Postero-anterior chest $\mathrm{X}$-ray revealed an anterior mediastinal mass. Laboratory investigations showed a hemoglobin value of $9.8 \mathrm{~g} / \mathrm{dl}$, white blood cell count of 12,970 cells $/ \mathrm{mm}^{3}$, and mild thrombocytosis of $550,000 / \mathrm{mm}^{3}$, with AST $25 \mathrm{U} / \mathrm{L}$, ALT $7 \mathrm{U} / \mathrm{L}$, BUN $2.2 \mathrm{mg} / \mathrm{dl}$, and $\mathrm{Cr} 0.13 \mathrm{mg} / \mathrm{dl}$. Serum AFP, BhCG and urinary spot VMA, HVA were all within normal limits. Thoracic computed 
tomography (CT) revealed a highly vascularized, hyperdense anterior superior mediastinal mass of $75 \times 46 \mathrm{~mm}$ in diameter with heterogeneous contrast enhancement (Fig. 1A) and also hypodense nodular lesions with the biggest of $10 \mathrm{~mm}$ in diameter throughout the lungs. There was also interstitial ground glass appearance all over the lungs. Abdominal CT scan showed multiple nodular hypodense lesions inside the liver with the biggest being $12 \mathrm{~mm}$ in diameter (Fig. 1D). There were no pathological lymph nodes or signs of bone involvement in thoracal and abdominal CT images. An ultrasound guided trucut biopsy was obtained from the mediastinal mass. Histopathological examination showed that the lesion was composed of clefted, grooved, irregular or convoluted nuclei with fine chromatin, one or more small nucleoli and moderate to abundant quantities of eosinophilic cytoplasm admixed with eosinophils. Immunohistochemically, the lesional cells were positive for Langerin, CD $1 \mathrm{a}$ and S-100, but negative for CD30, CD20, CD3, myeloperoxidase and EMA (Figs. $2 \mathrm{~A}, \mathrm{~B}, \mathrm{C})$. Although normal thymus tissue can also contain Langerhans cells positive for CD1a and Langerin, light microscopy findings revealing a neoplastic lesion combined with immunohistochemical staining clearly indicated a diagnosis of $\mathrm{LCH}$. Bone marrow aspiration and biopsy revealed no infiltration. The patient was treated with prednisolone and vinblastine with a diagnosis of $\mathrm{LCH}$-multisystem disease involving the thymus, lungs, liver and skin. After the second course of treatment, he was found to be in partial remission with amorphous calcification areas in the thymus, $18 \times 15 \mathrm{~mm}$ cystic lesions in the anterior mediastinum, and in the right medial and lingular segments of the lungs (Fig.1B, 1C). There were also nodular lesions with a biggest diameter of 8 $\mathrm{mm}$ within the liver which showed regression in number and size. After completion of his chemotherapy, he relapsed locally in the thymus after 8 months. Positron emmission tomography showed increased uptake and thorascopic biopsy demonstrated $\mathrm{LCH}$ recurrence. He received Cladribine for salvage therapy resulting in remission again. He has been in complete remission for 6 months after completion of salvage chemotherapy and for 3 years since his first admission.

\section{Discussion}

Langerhans cell histiocytosis is a clonal proliferative condition of Langerhans cells, which are members of macrophage/monocyte lineage and act as antigen-presenting cells ${ }^{6}$. $\mathrm{LCH}$ is characterized by excess accumulation of pathologic Langerhans cells in a variety of tissues. The disease varies widely in clinical presentation from localized involvement of a single bone to a widely disseminated lifethreatening disease ${ }^{7}$.

Langerhans cell histiocytosis is usually classified as a single-system or multi-system disease. Multi-system disease occurs most frequently in those under 2 years old, is often associated with fever, constitutional symptoms and failure to thrive ${ }^{6}$ and is usually associated with cutaneous presentation ${ }^{8}$. High risk patients are those with two or more risk organ involvement, such as liver, spleen, lung or hematopoetic system $^{7}$. Thymus gland involvement in $\mathrm{LCH}$ has been published in pathology and radiology case reports and in small series. It is usually part of multi-system disease and may be more common than previously recognized ${ }^{3,4}$. However, thymic involvement causing an anterior mediastinal mass is an extremely rare presentation of multisystem $\mathrm{LCH}^{1,3,9}$. Granulomatous infiltration of the thymus by dendritic cells is common in pediatric $\mathrm{LCH}$, especially in multi-system disease, and may result in the formation of an anterior mediastinal mass ${ }^{10}$. The mediastinal mass may appear as calcified, cystic and cavitary lesions or as hypodense soft tissue masses on CT scans. Although uncommon, the presence of punctate calcifications and cavitary air cysts in an enlarged thymus are highly specific for LCH when seen ${ }^{9,11}$. Our patient was presented with a huge anterior mediastinal mass which reduced in size after the second course of treatment with the appearance of cystic lesions in the tumor and amorphous calcification areas in the thymus. So, the initial diagnosis was mediastinal LCH with thymic involvement and the patient was in partial remission after chemotherapy. There are only few cases describing mediastinal masses in infants with LCH in the literature. In a cohort of Ducassou et al. ${ }^{5}$ the rarity of thymic and/or mediastinal involvement is mentioned. The proportion was dependent on age, ranging from $7 \%$ in infants 


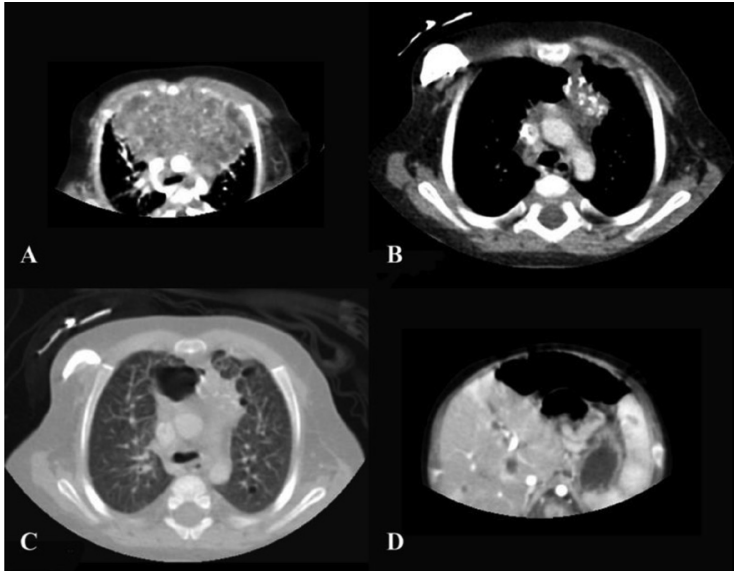

Fig. 1. Axial plan CT of the chest and abdomen. A. Large anterior mediastinal mass with low enhancement and tiny calcifications. B. Markedly shrinked mass lesion with some amorf calcifications after chemotherapy. C. Lung parenchyma showing multiple cysts and cavitations which appear after treatment. D. Multiple hypodense nodular lesions in liver parenchyma.

less than 1 year of age, decreasing to less than $1 \%$ in older children ${ }^{5}$. The referral to hospital with symptoms of mediastinal involvement are mostly during infancy. There are 22 patients diagnosed during the first year of life in the literature with mediastinal involvement ${ }^{5} ; 9$ of the infants had respiratory symptoms like our patient. Mediastinal involvement was almost always associated with multi-systemic disease as in our patient. Hatakeyama et al. ${ }^{4}$ reported a 2-month-old baby who was diagnosed to have skin-only LCH at the age of 6 months followed without any treatment. His cutaneous LCH gradually regressed but relapsed with isolated thymic involvement when he was 11 months old. His chest X-ray revealed mediastinal enlargement and computed tomography of the chest showed thymic enlargement with punctuate calcifications and heterogeneous contrast enhancement. He was successfully treated with chemotherapy and respiratory symptoms resolved. Our patient had also presented with similar skin lesions except for early regression of the lesions which were thought to be non-specific.

Spontaneous regression of LCH skin lesions is not uncommon. Congenital self-healing reticulohistiocytosis, self-limited variant of $\mathrm{LCH}$ with only skin involvement, has a characteristic of presence of cutaneous lesions such as papules, nodules and vesicles, usually at birth or in the neonatal period, without any systemic

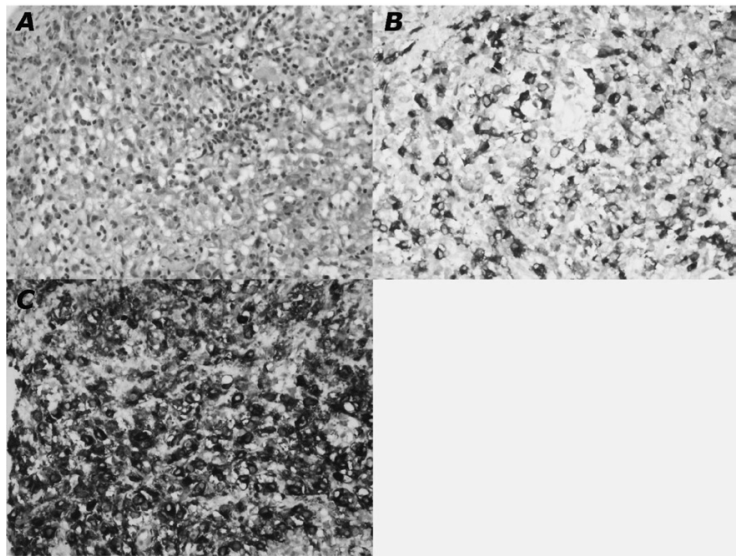

Fig. 2. A. Lesional cells with eosinophilic cytoplasm and grooved nuclei admixed with eosinophils (HE, original magnification $\times 200$ ) B. Lesional cells stained positive for Langerin (original magnification $\mathrm{x} 400$ ) C. Strong immunoreactivity for CD1a (original magnification $\times 400$ )

involvement. Spontaneous involution and absence of systemic symptoms are marked characteristics for differential diagnosis with the other clinical spectra of $\mathrm{LCH}^{12}$. Despite many studies showing spontaneous resolution 12-14, there may be dissemination or relapse of the illness in some cases, demonstrating that the clinical course is quite variable and a longterm follow-up is essential ${ }^{4,15,16}$. In a neonatal cohort of $\mathrm{LCH}$ by Minkov et al. ${ }^{17}$, the rate of spontaneous regression in the non-treated patients with cutaneous SS-LCH was $56 \%$ (5 of 9 patients), while disease progression requiring systemic therapy and reactivation was observed in 4 and 2 patients, respectively ${ }^{17}$.

Picarsic J et al. ${ }^{18}$ described 4 distinct histologic patterns of Langerhans cell proliferations and $\mathrm{LCH}$ of the thymus with relevance for diagnosis and treatment ${ }^{18}$. Group 1 consists of LCH-like hyperplasia found during incidental thymectomy or as an incidental finding during unrelated computed tomography (CT) imaging. None had evidence of LCH disease, either at the time of diagnosis or in subsequent follow-up. Single system LCH of the thymus differs from the incidental LCH-like hyperplasia largely in the extent of the process within the thymus, based on gland destruction with necrosis and punctate calcifications and a surrounding fibrotic response makes Group 2. Involvement in MS LCH represents the largest group of thymic LCH. Although many MS LCH cases in the literature do not describe the histologic pattern of thymic LCH involvement, thymic 
involvement of MS LCH occurs predominately in the youngest $(<1$ year) patients with $\mathrm{LCH}$, both with and without systemic symptoms, but all with active disease, showing higher rates of reactivation and mortality. Group 4 are mixed histiocytic disorders including JXG lesions occurring after $\mathrm{LCH}$, and are very rare. Since the biopsy material was too small to reach a definitive decision histologically, according to the study, our patient probably falls into Group 3 defined by variable histologic thymic involvement, from confined medullary $\mathrm{LCH}$ aggregates to architectural disruption in the context of MS LCH, requiring systemic therapy and having worse survival rates. Age of our patient being $<1$ year of age and showing recurrence are consistent with Group 3.

The prognosis of LCH depends on the patient's age, the presence of organ involvement at the time of diagnosis, the presence and severity of organ dysfunction and involvement of high risk organs, (hematopoietic system, liver, spleen and lung) and the response to treatment during the disease course ${ }^{4,8}$. Involvement of the hematopoietic system, liver, spleen and lung is seen predominantly in children $<2$ years old. Ducassau et al. ${ }^{5}$ conclude that mediastinal involvement was always associated with multi systemic diseases, with half of them having affected risk organs. Although thymic involvement may result in significant adverse symptoms, it is not considered as a major organ determining the prognosis. The deaths were rather due to already known risk organs, supportive care and/ or toxicity of second-line therapy in the cohort ${ }^{5}$. On chest radiography, early stages of pulmonary involvement present as a nodular pattern, with nodule diameters ranging from 1 to $10 \mathrm{~mm}$. In later stages, the nodular pattern is replaced by a coarse reticular pattern caused by cystic lesions ${ }^{19}$. In our patient, multisystem involvement including lung and liver, young age and partial remission after chemotherapy can all be considered as adverse prognostic factors.

To our knowledge, our case is the youngest patient to have a mediastinal mass due to thymic involvement of $\mathrm{LCH}$ who survived. The differential diagnosis of mediastinal mass in children should also include LCH, especially multi-system disease. On the other hand, skin lesions in infants can be the only presenting symptom which usually shows spontaneous regression before a definitive diagnosis is made. LCH should be kept in mind in the differential diagnosis of skin lesions in infants, and a careful evaluation for systemic disease with close follow-up for relapses is essential even in patients with spontaneous resolution of the disease.

\section{REFERENCES}

1. Siddaiah R, Weinblatt $\mathrm{M}$, Roberts J, Cataletto $M$. Anterior mediastinal bone-eroding mass with disseminated lung lesions. Chest 2011; 140; 1371-1376.

2. Pizzo PA, Poplack DG. Principles and Practice of Pediatric Oncology, 6th ed. Philedelphia: Lippincott Williams and Wilkins 2011: 703-716.

3. Junewick JJ, Fitzgerald NE. The thymus in Langerhans cell histiocytosis. Pediatr Radiol 1999; 29: 904-907.

4. Hatakeyama N, Hori T, Yamamoto M, et al. An infant with self-healing cutaneous Langerhans cell histiocytosis followed by isolated thymic relapse. Pediatr Blood Cancer 2009: 53; 229-231.

5. Ducassou S, Seyrig F, Thomas C, et al. Thymus and mediastinal node involvement in childhood langerhans cell histicytosis: Long-term follow-up from the French National Cohort. Pediatr Blood Cancer 2013; 60: 17591765.

6. Elliott M, Kokai GK, Abernethy LJ, Pizer BL. Spontaneous resoluton of isolated thymic langerhans cell histiocytosis. Med Pediatr Oncol 2002; 38: 274 276.

7. Weitzman S, Egeler RM. Langerhans cell histiocytosis: update for the pediatrician. Current Opin in Pediatr 2008; 20: 23-29.

8. Lucioni M, Beluffi G, Bandiera L, et al. Congenital aggressive variant of Langerhans Cells histiocytosis with CD56+/E-Cadherin- phenotype. Pediatr Blood Cancer 2009; 53: 1107-1110.

9. Abramson SJ, Berdon WE, Reilly BJ, Kuhn JP. Cavitation of anterior mediastinal masses in children with histiocytosis-X. Report of four cases with radiographic, pathologic finding and clinical follow-up. Pediatr Radiol 1987; 17: 10-14.

10. Crawley AJ, Guillerman RP. Langerhans cell histiocytosis with intrathymic calcifications and cavitation. Pediatr Radiol 2010; 40(Suppl 1): S62.

11. Heller GD, Haller JO, Berdon WE, Sane S, Kleinman PK. Punctate thymic calcification in infants with untreated langerhans' cell histiocytosis: report of four new cases. Pediatr Radiol 1999; 29: 813-815.

12. Orle J, Mosca AM, Sousa MAJ, Lima CM, Adriano AR, Rezende PM. Congenital self healing reticulohistiocytosis in a newborn (Hashimato Pritzker). An Bras Dermatol 2011; 86: 785-788.

13. Kapur P, Erickson C, Rakheja D, Carder KR, Hoang MP. Congenital self-healing reticulohistiocytosis (Hashimato-Pritzker disease): ten year experience at Dallas Children's Medical Center. J Am Acad Dermatol 2007; 56: 290-294. 
14. Walia M, Paul P, Mishra S, Mehta R. Congenital Langerhans cell histicytosis: The self-healing variety. J Pediatr Hematol Oncol 2004; 26: 398-402.

15. Jensen MLS, Bygum A, Clemmensen O, Fenger-Gron J. Congenital self-healing reticulohistiocytosis-an important diagnostic challenge. Acta Paediatr 2011; 100; 784-786.

16. Aggarwal V, Seth A, Jain M, Krishnamurthy S, Chandra V, Aneja S. Congenital Langerhans Cell histiocytosis with skin and lung involvement: Spontaneous regression. Indian J Pediatr 2010; 77: 811-812.

17. Minkov M, Prosch H, Steiner M, et al. Langerhans cell histiocytosis in neonates. Pediatr Blood Cancer 2005; 45: 802-807.
18. Picarsic J, Egeler RM, Chikwava K, Patterson K and Jaffe R. Histologic patterns of thymic involvement in Langerhans cell proliferations: A clinicopathologic study and review of the literature. Pediatr Dev Pathol 2015; 18: 127-138.

19. Ronceray L, Pötschger U, Janka G, Gadner H, Minkov M; German Society for Pediatric Hematology and Oncology, Langerhans Cell Histiocytosis Study Group. Pulmonary involvement in pediatric-onset multisystem Langerhans cell histiocytosis: effect on course and outcome. J Pediatr 2012; 161: 129-133. e1-e3. 